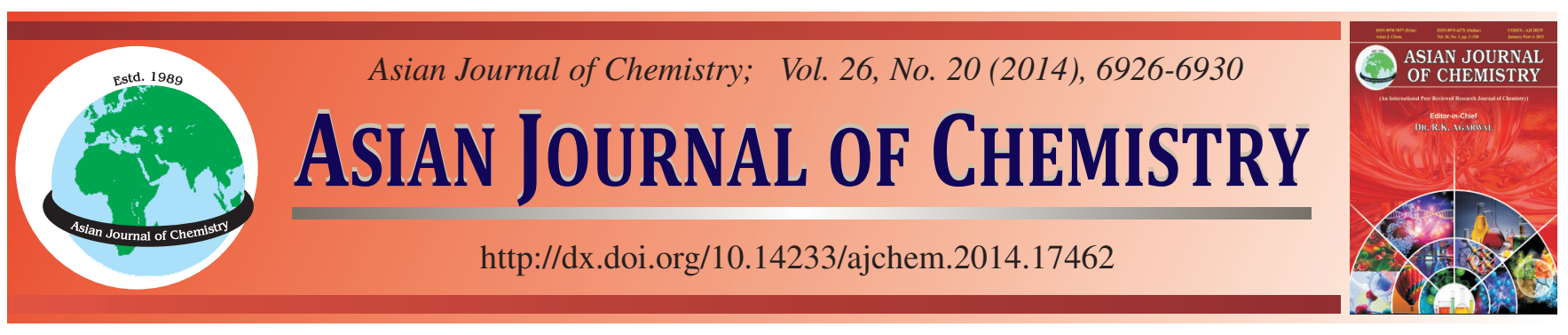

\title{
DFT Studies on the Molecular Structure, Electronic and Spectroscopic Properties of Free and Zinc(II) Coordinated N-Alkyl Thiourea Ligands
}

\begin{abstract}
SAiEd M. Soliman ${ }^{1,2, *}$ and Ahmed A. BAdR ${ }^{2, *}$
${ }^{1}$ Department of Chemistry, Rabigh College of Science and Art, King Abdulaziz University, Rabigh, Saudi Arabia

${ }^{2}$ Department of Chemistry, Faculty of Science, Alexandria University, P.O. Box 426 Ibrahimia, 21525 Alexandria, Egypt

*Corresponding authors: Tel.: +966 565450752; E-mail: saied1soliman@yahoo.com

Received: 25 February 2014;

Accepted: 26 June 2014;

Published online: 25 September 2014;

AJC-16041

The molecular structure, vibrational spectra and non linear optical properties of five thiourea ligands $(\mathrm{L})$ and their zinc chloride complexes; $\left[\mathrm{ZnL}_{2} \mathrm{Cl}_{2}\right]$ are calculated using DFT/B3LYP method. The results of calculations showed an increase of the C-N double bond characters and decrease of the $\mathrm{C}$-S bond order due to the coordination between $\mathrm{Zn}^{2+}$ and thiourea ligands through the $\mathrm{S}$-atom. A low frequency shift for the $v(\mathrm{C}-\mathrm{S})$ bands and high frequency shift for $\mathrm{v}(\mathrm{C}-\mathrm{N})$ bands are predicted in case of the zinc(II) complexes compared to the free ligands. Also, red shifts for the $\mathrm{v}(\mathrm{N}-\mathrm{H})$ stretches involved in the formation of intramolecular $\mathrm{NH}---\mathrm{Cl} \mathrm{H}$-bonds while the rest of the $v(\mathrm{~N}-\mathrm{H})$ modes undergo blue shifts. High polar character of the $\mathrm{C}-\mathrm{N}$ and $\mathrm{C}-\mathrm{S}$ bonds is predicted. Molecular electrostatic potential predicted the higher reactivity of the $\mathrm{S}$-site of the thiourea ligands towards electrophilic attack compared to the $\mathrm{N}$-sites.

Keywords: Thiourea, DFT, Vibrational spectra, Intramolecular H-bond, Non-linear optical.
\end{abstract}

\section{INTRODUCTION}

The study of thiourea and its N-substituted derivatives have great interest ${ }^{1}$ in view of the potential use of these compounds as highly selective reagents for the separation of metal cations ${ }^{1}$ and in biological applications such as their use as antibacterial, antiviral or antifungal agents ${ }^{2,3}$. Also the importance of these thioamides is due to the relevance of their binding sites to those in living systems ${ }^{2}$. Their transition metal complexes are also subject of interest due to the special roles played by these compounds in biological processes ${ }^{1,4,5}$.

The coordination occurs between the metal with sulphur rather than between the metal and nitrogen ${ }^{6}$. It is also found that thiourea ligands can exist in the highly polar structure (Fig. 1). The molecular structure of these compounds is considered to be a resonance hybrid with this highly polar structure. In this work, the molecular structure and vibrational spectra of thiourea (TU), N-methylthiourea (MTU), N,N'dimethylthiourea (DMTU), tetramethylthiourea (TMTU), diazinane-2-thione (DAT); (Fig. 1) and their zinc chloride complexes $\left[\mathrm{ZnL}_{2} \mathrm{Cl}_{2}\right]$ are calculated using DFT/B3LYP/6$311+\mathrm{G}(\mathrm{d}, \mathrm{p})$ method. The aim of this work is to explain the effect of $\mathrm{N}$-alkyl substitution and metal ion coordination on the molecular structure, reactivity, electronic and spectroscopic properties of these compounds using DFT/B3LYP method.

\section{COMPUTATIONAL METHODS}

All calculations for the ligands $(\mathrm{L})$ and their $\left[\mathrm{ZnL}_{2} \mathrm{Cl}_{2}\right]$ complexes were carried out using Gaussian 03 software $^{7}$ on Pentium IV processor personal computer. The calculations were performed using DFT/B3LYP/6-311+G(d,p) method. The starting input geometry of the $\left[\mathrm{ZnL}_{2} \mathrm{Cl}_{2}\right]$ complexes are taken from the crystallographic information file $(\mathrm{CIF})^{8}$ where tetrahedral coordination geometry around the zinc atom is considered $^{3,9}$. GausssView ${ }^{10}$ has been used to draw the structures of the optimized geometries and to make assignment for the vibrational modes.

\section{RESULTS AND DISCUSSION}

Stabilities, dipole moments $(\mu)$ and thermodynamic functions: The energies, dipole moments and thermodynamic functions of the thiourea ligands are shown in Table-1. It was reported that, N-methylthiourea and N,N'-dimethylthiourea exist in the cis-trans and trans-trans configuration, respectively $^{2,11}$. The DFT gas phase calculations predicted the cisconformer of $\mathrm{N}$-methylthiourea is more stable than the trans one while for N,N'-dimethylthiourea, the cis-trans conformer is more stable than the others. The results of energy analysis predicted the cis-conformer of $\mathrm{N}$-methylthiourea is more stable than the trans one by only $0.2199 \mathrm{kcal} / \mathrm{mole}$. The energy difference between the two conformers is very small which indicates 
<smiles>CN(P)C(N)=S</smiles>

TU

cis<smiles>CNC(N)=S</smiles>

trans<smiles>S=C1NCCCN1</smiles>

DAT<smiles>CN(C)C(=S)N(C)C</smiles>

TMTU<smiles>CNC(=S)NC</smiles>

trans-trans<smiles>CNC(=S)NC</smiles>

cis-cis<smiles>CNC(=S)NC</smiles>

cis-trans<smiles>[R]N([R])C([S-])=[N+]([R])[R]</smiles>

Dipolar structure of the studied thioamides

DMTU conformers

Fig. 1. Structure of the studied thiourea ligands (L)

their coexistence in equilibrium in the gas phase. For N,N'dimethylthiourea, the calculations showed that the cis-trans conformer is more stable than the trans-trans one by 0.5242 $\mathrm{kcal} / \mathrm{mol}$. In view of the relatively high $\Delta \mathrm{E}$ value of the cis-cis conformer, one can conclude that it should not be observed in the gas phase and the cis-trans conformer is the dominant species (Table-1). On other hand, the calculated dipole moment values indicate that the $\operatorname{cis}(\mathrm{MTU})$ is more polar than the trans(MTU) while for $\mathrm{N}, \mathrm{N}^{\prime}$-dimethylthiourea, the cis-trans conformer is more polar than the trans-trans one.

Molecular geometry: The optimized molecular structure of one of the studied thiourea ligands (L) and its $\left[\mathrm{ZnL}_{2} \mathrm{Cl}_{2}\right]$ complex as an example are shown in Fig. 2. Selected geometric parameters are summarized in Table-2. For thiourea, the C-S, C1-N3 and C1-N4 bond distances are calculated to be 1.671, 1.365 and $1.365 \AA$, respectively while for N-methyl-thiourea are predicted to be $1.681,1.363$ and $1.356 \AA$ respectively. One can conclude that the presence of $\mathrm{N}$-alkyl substitution increase the double bond character of the $\mathrm{C}-\mathrm{N}$ bonds while the single bond character of the $\mathrm{C}-\mathrm{S}$ bond is increased. For the $\left[\mathrm{ZnL}_{2} \mathrm{Cl}_{2}\right]$ complexes, the elongation of the $\mathrm{C}-\mathrm{S}$ bond and the shortening of the $\mathrm{C}-\mathrm{N}$ bonds increase as the $\mathrm{Zn}-\mathrm{S}$ interaction increase, in other word, the $\mathrm{Zn}-\mathrm{S}$ distances decrease. It is noted that the calculated values of the N9-H14 and N11-H18 distances in case of the complexes 1-4; are slightly longer than the rest of $\mathrm{N}-\mathrm{H}$ bonds. This could be attributed to the intramolecular $\mathrm{N}-\mathrm{H}$--- $\mathrm{Cl}$ interactions between the coordinated $\mathrm{Cl}$-atoms with $\mathrm{H} 14$ and $\mathrm{H} 18$ sites. These results are in good agreement with the available X-ray structure of the studied complexes ${ }^{8,9}$.
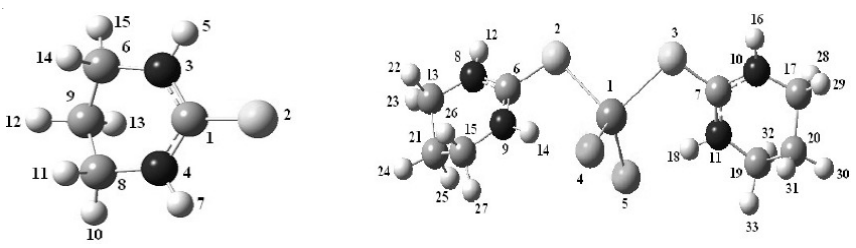

Fig. 2. B3LYP/6-311+G** optimized molecular geometries and atom numbering scheme of DAT and $\left[\mathrm{Zn}(\mathrm{DAT})_{2} \mathrm{Cl}_{2}\right]$ complexes

Atom polar tensor (APT) charges: Atom polar tensor charges of the studied compounds are calculated using B3LYP method. Selected APT charge values are given in Table-3. The $\mathrm{S}$ - and $\mathrm{N}$-sites are considerably affected by the presence of $\mathrm{N}$ alkyl substituent. The electron releasing N-methyl substituent $(+\mathrm{I})$ increases the negative charge density at the $\mathrm{N}$ and $\mathrm{S}$-atoms. The polar character of the C-S and C-N bonds of N-methylthiourea, N,N'-dimethylthiourea and diazinane-2-thione is slightly higher than that for thiourea ${ }^{6}$. Also, the coordination

\begin{tabular}{|c|c|c|c|c|c|c|c|c|}
\hline \multicolumn{9}{|c|}{$\begin{array}{l}\text { TABLE-1 } \\
\text { CALCULATED TOTAL ENERGIES, DIPOLE MOMENT }(\mu) \text {, THERMODYNAMIC FUNCTIONS AND } \\
\text { RELATIVE STABILITIES OF THE THIOUREA LIGANDS USING DFT/B3LYP/6-311G+(d,p) METHOD }\end{array}$} \\
\hline Compound & & $\begin{array}{c}{ }^{\mathrm{a}} \mathrm{E}_{\text {corr }} \\
\text { (Hartree) }\end{array}$ & $\begin{array}{c}\text { M } \\
\text { (Debye) }\end{array}$ & $\begin{array}{c}\mathrm{G} \\
\text { (Hartree) }\end{array}$ & $\begin{array}{c}\Delta \mathrm{E} \\
(\mathrm{kcal} / \mathrm{mol})\end{array}$ & $\begin{array}{c}\Delta \mathrm{G} \\
(\mathrm{kcal} / \mathrm{mol})\end{array}$ & $\mathrm{K}$ & $X$ \\
\hline Thiourea & - & -548.2413 & 5.009 & -548.2688 & & & & \\
\hline N-Methylthiourea & cis & -587.5300 & 5.835 & -587.5602 & 0 & 0 & - & 0.6420 \\
\hline \multirow{3}{*}{ N,N'-Dimethylthiourea } & cis-cis & -626.8102 & 5.469 & -626.8422 & 4.9117 & 5.5798 & 11584.164 & 0.0001 \\
\hline & cis-trans & -626.8180 & 5.740 & -626.8511 & 0 & 0 & - & 0.8149 \\
\hline & trans-trans & -626.8171 & 5.038 & -626.8497 & 0.5242 & 0.8842 & 4.405 & 0.1850 \\
\hline Diazinane-2-thione & - & -664.9301 & 6.426 & -664.9614 & & & & \\
\hline
\end{tabular}




\begin{tabular}{|c|c|c|c|c|c|c|c|c|c|c|c|c|}
\hline \multicolumn{13}{|c|}{$\begin{array}{c}\text { TABLE-2 } \\
\text { SELECTED BOND DISTANCES AND BOND ANGLES CALCULATED USING } \\
\text { THE B3LYP/6-311+G(d,p) METHOD FOR THE STUDIED COMPOUNDS }\end{array}$} \\
\hline Atoms & TU & MTU & DMTU & DAT & TMTU & Atoms & 1 & 2 & 3 & 4 & 5 & Exp. ${ }^{a}$ \\
\hline $\mathrm{C} 1-\mathrm{S} 2$ & 1.671 & 1.681 & 1.685 & 1.686 & 1.682 & $\mathrm{Zn} 1-\mathrm{S} 2$ & 2.460 & 2.443 & 2.445 & 2.434 & 2.469 & 2.341 \\
\hline $\mathrm{C} 1-\mathrm{N} 3$ & 1.365 & 1.363 & 1.363 & 1.358 & 1.378 & C6-S2 & 1.714 & 1.722 & 1.723 & 1.726 & 1.725 & 1.735 \\
\hline C1-N4 & 1.365 & 1.356 & 1.356 & 1.358 & 1.378 & Zn1-S3 & 2.457 & 2.443 & 2.445 & 2.439 & 2.482 & 2.341 \\
\hline N3-H6 & 1.007 & 1.008 & - & - & - & C6-N8 & 1.353 & 1.353 & 1.350 & 1.350 & 1.359 & 1.327 \\
\hline N4-H7 & 1.010 & 1.007 & 1.007 & 1.008 & - & C6-N9 & 1.331 & 1.328 & 1.335 & 1.330 & 1.351 & 1.327 \\
\hline N4-H8 & 1.007 & - & - & - & - & C7-N10 & 1.352 & 1.353 & 1.350 & 1.350 & 1.360 & 1.327 \\
\hline N3-C1-N4 & 114.650 & 115.987 & 115.890 & 116.430 & 114.862 & C7-N11 & 1.330 & 1.328 & 1.335 & 1.330 & 1.350 & 1.327 \\
\hline $\mathrm{S} 2-\mathrm{C} 1-\mathrm{N} 3$ & 122.675 & 121.983 & 120.999 & 121.779 & 122.572 & N8-H12 & 1.008 & 1.006 & 1.008 & 1.008 & - & 0.885 \\
\hline \multirow[t]{8}{*}{ S2-C1-N4 } & 122.676 & 122.017 & 123.111 & 121.779 & 122.566 & N8-H13 & 1.006 & 1.007 & - & - & - & \\
\hline & & & & & & N9-H14 & 1.028 & 1.028 & 1.026 & 1.027 & 0.882 & \\
\hline & & & & & & N10-H16 & 1.006 & 1.006 & 1.008 & 1.008 & 0.882 & \\
\hline & & & & & & N10-H17 & 1.008 & 1.007 & - & - & - & \\
\hline & & & & & & N11-H18 & 1.028 & 1.028 & 1.026 & 1.027 & 0.882 & \\
\hline & & & & & & N11-H19 & 1.009 & - & - & - & - & \\
\hline & & & & & & H14---Cl4 & 2.137 & 2.130 & 2.148 & 2.140 & 2.339 & \\
\hline & & & & & & H18---Cl5 & 2.130 & 2.130 & 2.148 & 2.160 & 2.339 & \\
\hline
\end{tabular}

[Ref. 8] complexes 1-5

TU: Thiourea, MTU: N-methylthiourea, DMTU: N,N'-dimethylthiourea, DAT: diazinane-2-thione, TMTU: tetramethylthiourea

TABLE-3

CALCULATED APT CHARGES AT VARIOUS ATOMIC SITES FOR THE STUDIED THIOUREA LIGANDS; L AND THEIR COORDINATION COMPLEXES; $\left[\mathrm{ZnL}_{2} \mathrm{Cl}_{2}\right]$ USING DFT METHOD

\begin{tabular}{|c|c|c|c|c|c|c|c|c|c|c|c|}
\hline Atom & $\mathrm{TU}$ & MTU & DMTU & DAT & TMTU & Atom & 1 & 2 & 3 & 4 & 5 \\
\hline \multirow[t]{2}{*}{$\mathrm{C} 1$} & 1.1854 & 1.1897 & 1.1698 & 1.1769 & 1.1384 & C6 & 1.2166 & 1.1758 & 1.1774 & 1.1601 & 1.1743 \\
\hline & & & & & & C7 & 1.2247 & 1.1760 & 1.1774 & 1.1458 & 1.1643 \\
\hline \multirow[t]{2}{*}{ S2 } & -0.5967 & -0.6508 & -0.6314 & -0.6875 & -0.5998 & S2 & -0.6336 & -0.6629 & -0.6526 & -0.6974 & -0.7071 \\
\hline & & & & & & S3 & -0.6309 & -0.6629 & -0.6526 & -0.6982 & -0.6913 \\
\hline \multirow[t]{2}{*}{$\mathrm{N} 3$} & -0.7247 & -0.7036 & -0.7216 & -0.7326 & -0.7991 & N8 & -0.7793 & -0.7793 & -0.7836 & -0.8061 & -0.7315 \\
\hline & & & & & & N9 & -0.8027 & -0.8085 & -0.8486 & -0.7960 & -0.7924 \\
\hline \multirow[t]{2}{*}{$\mathrm{N} 4$} & -0.7246 & -0.7528 & -0.7795 & -0.7326 & -0.7991 & N10 & -0.7823 & -0.7795 & -0.7836 & -0.7891 & -0.7282 \\
\hline & & & & & & N11 & -0.8124 & -0.8086 & -0.8486 & -0.7869 & -0.7933 \\
\hline \multirow[t]{2}{*}{ H5 } & 0.2273 & 0.2332 & 0.1540 & 0.1952 & - & H12 & 0.2176 & 0.2155 & 0.1638 & 0.2138 & - \\
\hline & & & & & & H13 & 0.2511 & 0.2557 & - & - & - \\
\hline \multirow[t]{2}{*}{ H6 } & 0.2031 & 0.1964 & - & - & - & H14 & 0.4057 & 0.3713 & 0.3667 & 0.3894 & - \\
\hline & & & & & & H15 & 0.2090 & - & - & - & - \\
\hline \multirow[t]{2}{*}{$\mathrm{H} 7$} & 0.2273 & 0.1903 & 0.1890 & 0.1952 & - & H16 & 0.2192 & 0.2156 & 0.1638 & 0.2099 & - \\
\hline & & & & & & H17 & 0.2532 & 0.2558 & - & - & - \\
\hline \multirow[t]{5}{*}{$\mathrm{H} 8$} & 0.2030 & - & - & - & - & H18 & 0.4090 & 0.3714 & 0.3667 & 0.3811 & - \\
\hline & & & & & & H19 & 0.2079 & - & - & - & - \\
\hline & & & & & & $\mathrm{Zn}$ & 1.3639 & 1.3569 & 1.3822 & 1.3708 & 1.3514 \\
\hline & & & & & & $\mathrm{Cl}$ & -0.7683 & -0.7740 & -0.7811 & -0.7813 & -0.7268 \\
\hline & & & & & & $\mathrm{Cl}$ & -0.7683 & -0.7740 & -0.7811 & -0.7875 & -0.7323 \\
\hline
\end{tabular}

TU: Thiourea, MTU: N-methylthiourea, DMTU: N,N'-dimethylthiourea, DAT: diazinane-2-thione, TMTU: tetramethylthiourea

of the $\mathrm{Zn}^{2+}$ with the $\mathrm{S}$-atom of the ligand further increases the polar character of these bonds. Moreover, it is found that the formation of $\mathrm{N}-\mathrm{H}---\mathrm{Cl}$ intramolecular $\mathrm{H}$-bonding interactions increases the charge density at the H14 and H18 atoms (almost twice) compared to the other $\mathrm{H}$-atoms. As a result the charge densities at the neighboring N-atoms (N9 and N11) are shifted to more negative charge densities than the corresponding $\mathrm{N} 8$ and N10 atoms.

Molecular electrostatic potential (MEP): The molecular electrostatic potential (MEP) is used to study the electrophilic reactivity of the studied thiourea ligands towards attack by positive metal ion such as $\mathrm{Zn}^{2+}$ electrophile. The most negative regions are associated with S-atom (-0.0382 to $-0.0471 \mathrm{a}$ a) rather than the $\mathrm{N}$-atom $(+0.0085$ to -0.0145 a.u). From this point of view, the reactivity of the S-site toward electrophilic attack by a positive metal ion such as $\mathrm{Zn}^{2+}$ electrophile is more favored than $\mathrm{N}-$ site $^{3}$ where the former offer more negative electrostatic potential than the latter.

Vibrational spectra: The fundamental vibration modes of the studied compounds are given in Table-4. The calculated harmonic frequencies are scaled down by multiplying their values by a factor of $0.9679^{12}$.

N-H stretching modes: In order to evaluate the effect of the metal ion coordination on the vibrational spectra of the studied thioamides, the shifts in the vibrational frequencies $\left(\Delta v_{i}^{\text {Scal }}\right)$ and intensities $\left(\Delta \mathrm{A}_{\mathrm{i}}\right)$ due to complex formation have been calculated by using equations proposed by Destexhe et $a l .{ }^{13}$ and the results are given in Table-5. It can be seen that 


\begin{tabular}{|c|c|c|c|c|c|c|c|c|c|c|c|c|c|c|c|c|}
\hline \multirow{3}{*}{ No. } & \multicolumn{15}{|c|}{$\begin{array}{c}\text { TABLE-4 } \\
\text { SELECTED STRETCHING VIBRATIONAL FREQUENCIES }(\mathrm{v})\left(\mathrm{cm}^{-1}\right) \text { AND } \\
\text { VIBRATIONAL INTENSITIES }(A)\left(\mathrm{km} \mathrm{mol}^{-1}\right) \text { FOR THE STUDIED COMPOUNDS }\end{array}$} & \multirow{3}{*}{ Assig } \\
\hline & \multicolumn{3}{|c|}{$\mathrm{TU}$} & \multicolumn{3}{|c|}{ MTU } & \multicolumn{3}{|c|}{ DMTU } & \multicolumn{3}{|c|}{ DAT } & \multicolumn{3}{|c|}{ TMTU } & \\
\hline & Unscal. & Scal. & A & Unscal. & Scal. & A & Unscal. & Scal. & A & Unscal. & Scal. & A & Unscal. & Scal. & A & \\
\hline 1 & 3694 & 3575 & 24.4 & 3709 & 3590 & 50.1 & 3651 & 3534 & 54.9 & 3642 & 3525 & 8.1 & - & - & - & $v_{\mathrm{NH}}$ \\
\hline 2 & 3693 & 3574 & 68.9 & 3648 & 3531 & 53.1 & & & & & & & - & - & - & $v_{\mathrm{NH}}$ \\
\hline 3 & 3568 & 3453 & 13.6 & 3580 & 3465 & 29.6 & 3626 & 3510 & 20.0 & 3637 & 3520 & 91.3 & - & - & - & $v_{\mathrm{NH}}$ \\
\hline 4 & 3560 & 3446 & 46.7 & - & - & - & - & - & - & - & - & - & - & - & - & $v_{\mathrm{NH}}$ \\
\hline 5 & 1419 & 1373 & 110.6 & 1543 & 1493 & 377.3 & 1571 & 1521 & 277.4 & 1574 & 1523 & 292.9 & 1395 & 1350 & 199.5 & $v_{\mathrm{CN}}$ \\
\hline 6 & 1405 & 1360 & 320.8 & 1414 & 1369 & 18.1 & 1359 & 1315 & 111.9 & 1343 & 1300 & 65.5 & 1376 & 1332 & 184.7 & $v_{\mathrm{CN}}$ \\
\hline \multirow[t]{2}{*}{7} & 766 & 741 & 11.7 & 795 & 769 & 32.1 & 736 & 712 & 4.6 & 585 & 566 & 8.4 & 627 & 607 & 0.3 & $v_{\mathrm{CS}}$ \\
\hline & \multicolumn{3}{|c|}{1} & \multicolumn{3}{|c|}{2} & \multicolumn{3}{|c|}{3} & \multicolumn{3}{|c|}{4} & \multicolumn{3}{|c|}{5} & \\
\hline 1 & 3720 & 3601 & 58.5 & 3723 & 3603 & 60.2 & - & - & - & - & - & - & - & - & - & $v_{\mathrm{NH}}$ \\
\hline 2 & 3716 & 3597 & 56.9 & 3723 & 3603 & 57.8 & - & - & - & - & - & - & - & - & - & $v_{\mathrm{NH}}$ \\
\hline 3 & 3634 & 3517 & 41.4 & - & - & - & - & - & - & - & - & - & - & - & - & $v_{\mathrm{NH}}$ \\
\hline 4 & 3633 & 3516 & 123.9 & - & - & - & - & - & - & - & - & - & - & - & - & $v_{\mathrm{NH}}$ \\
\hline 5 & 3591 & 3476 & 64.4 & 3599 & 3483 & 38.6 & 3633 & 3516 & 1.7 & - & - & - & - & - & - & $v_{\mathrm{NH}}$ \\
\hline 6 & 3587 & 3472 & 63.6 & 3598 & 3483 & 89.9 & 3633 & 3516 & 72.7 & 3639 & 3522 & 59.9 & - & - & - & $v_{\mathrm{NH}}$ \\
\hline 7 & 3252 & 3148 & 847.5 & 3260 & 3155 & 1431.1 & 3294 & 3188 & 1428.1 & 3638 & 3521 & 60.1 & - & - & - & $v_{\mathrm{NH}}$ \\
\hline 8 & 3247 & 3143 & 830.9 & 3260 & 3155 & 270.4 & 3293 & 3187 & 266.2 & 3280 & 3175 & 898.9 & - & - & - & $v_{\mathrm{NH}}$ \\
\hline 9 & 1511 & 1462 & 106.6 & 1625 & 1573 & 242.3 & 1620 & 1568 & 297.4 & 3272 & 3167 & 865.3 & 1572 & 1522 & 247.9 & $v_{\mathrm{CN}}$ \\
\hline 10 & 1509 & 1461 & 104.1 & 1622 & 1570 & 269.4 & 1618 & 1566 & 247.8 & 1631 & 1579 & 129.8 & 1570 & 1520 & 255.9 & $v_{\mathrm{CN}}$ \\
\hline 11 & 1404 & 1359 & 6.4 & 1440 & 1394 & 35.7 & 1392 & 1347 & 75.4 & 1627 & 1575 & 258.6 & 1423 & 1377 & 105.6 & $v_{\mathrm{CN}}$ \\
\hline 12 & 1399 & 1354 & 593.3 & 1439 & 1393 & 40.7 & 1392 & 1347 & 51.1 & 1349 & 1306 & 53.6 & 1421 & 1375 & 116.1 & $v_{\mathrm{CN}}$ \\
\hline 13 & 728 & 705 & 6.9 & 782 & 757 & 59.7 & 727 & 704 & 5.2 & 1349 & 1306 & 59.2 & 616 & 596 & 2.4 & $v_{\mathrm{CS}}$ \\
\hline 14 & 727 & 704 & 62.0 & 781 & 756 & 6.6 & 727 & 704 & 7.1 & 576 & 558 & 5.5 & 615 & 595 & 10 & $v_{\mathrm{CS}}$ \\
\hline
\end{tabular}

TU: Thiourea, MTU: N-methylthiourea, DMTU: N,N'-dimethylthiourea, DAT: diazinane-2-thione, TMTU: tetramethylthiourea

TABLE-5

CALCULATED CHANGES IN THE VIBRATIONAL FREQUENCIES $\left(\Delta v^{\text {Scal }}\right)$ AND

VIBRATIONAL INTENSITIES $(\Delta \mathrm{A})$ FOR THE STUDIED $\left[\mathrm{ZnL}_{2} \mathrm{Cl}_{2}\right]$ COMPLEXES

\begin{tabular}{|c|c|c|c|c|c|c|c|c|c|c|}
\hline \multirow{2}{*}{$\Delta v^{\mathrm{com}} / \Delta v^{\mathrm{mon}}$} & \multicolumn{2}{|c|}{1} & \multicolumn{2}{|c|}{$2^{a}$} & \multicolumn{2}{|c|}{$3^{\mathrm{b}}$} & \multicolumn{2}{|c|}{$4^{b}$} & \multicolumn{2}{|c|}{5} \\
\hline & $\Delta v^{\text {cal }}$ & $\Delta \mathrm{A}$ & $\Delta v^{\text {scal }}$ & $\Delta \mathrm{A}$ & $\Delta v^{\text {scal }}$ & $\Delta \mathrm{A}$ & $\Delta v^{\text {scal }}$ & $\Delta \mathrm{A}$ & $\Delta \nu^{\text {scal }}$ & $\Delta \mathrm{A}$ \\
\hline$v_{1} / v_{1}$ & 25 & 34.1 & 14 & 10.1 & - & - & - & - & - & - \\
\hline$v_{2} / v_{1}$ & 21 & 32.5 & 14 & 7.7 & - & - & - & - & - & - \\
\hline$v_{3} / v_{2}$ & -57 & -27.5 & - & - & - & - & - & - & - & - \\
\hline$v_{4} / v_{2}$ & -58 & 55.0 & - & - & - & - & - & - & - & - \\
\hline$v_{5} / v_{3}$ & 22 & 50.8 & 18 & 9.0 & 7 & -18.3 & 2 & -31.4 & - & - \\
\hline$v_{6} / v_{3}$ & 18 & 50.0 & 17 & 60.3 & 7 & 52.7 & 1 & -31.2 & - & - \\
\hline$v_{7} / v_{4}$ & -298 & 800.8 & -376 & 1378.0 & -346 & 1373.2 & -350 & 890.8 & - & - \\
\hline$v_{8} / v_{4}$ & -303 & 784.2 & -376 & 217.3 & -347 & 211.3 & -358 & 857.2 & - & - \\
\hline$v_{9} / v_{5}$ & 89 & -4.0 & 79 & -135.0 & 47 & 20.0 & 55 & -163.1 & 171 & 48.4 \\
\hline$v_{10} / v_{5}$ & 87 & -6.5 & 76 & -107.9 & 45 & -29.6 & 51 & -34.3 & 169 & 56.4 \\
\hline$v_{11} / v_{6}$ & -1 & -314.4 & 25 & 17.6 & 32 & -36.5 & 6 & -11.9 & 45 & -79.1 \\
\hline$v_{12} / v_{6}$ & -6 & 272.5 & 24 & 22.6 & 32 & -60.8 & 6 & -6.3 & 44 & -68.6 \\
\hline$v_{13} / v_{7}$ & -37 & -4.8 & -13 & 27.6 & -9 & 0.6 & -9 & -2.9 & -11 & 0.3 \\
\hline$v_{14} / v_{7}$ & -38 & 50.3 & -14 & -25.5 & -9 & 2.5 & -11 & 14.1 & -12 & 0.3 \\
\hline
\end{tabular}

${ }^{a}$ Modes $v_{7} / v_{2}$ and $v_{8} / v_{2} ;{ }^{b}$ Modes $v_{7} / v_{1}$ and $v_{8} / v_{1}$

the coordination of the metal ion to the $S$-atom leads to blue shift in the N-H stretching frequencies (modes $v_{1}, v_{2}, v_{5}$ and $v_{6}$ ) where the formation of $\mathrm{S} \rightarrow \mathrm{M}$ bonds in all complexes under investigation increases the contribution of the highly polar structure to the thioamide molecules ${ }^{3,6}$. On other hand, the formation of N-H---Cl intramolecular H-bonding between N9$\mathrm{H} 14$ and N11-H18 with the coordinated chlorine atoms reduces the $\mathrm{N}-\mathrm{H}$ bond order. As a result these $\mathrm{N}-\mathrm{H}$ stretching vibrations undergo red shift and increase in their vibrational intensities up to 111 times in case of $\left[\mathrm{ZnL}_{2} \mathrm{Cl}_{2}\right]$ complexes; $\mathbf{1 - 4}$ (modes $\mathrm{v}_{3}, \mathrm{v}_{4}$, $v_{7}$ and $v_{8}$ ) compared to the free ligands (modes $v_{2}$ and $\left.v_{4}\right)^{14}$.
$\mathbf{C}=\mathbf{S}$ and $\mathbf{C}-\mathbf{N}$ stretching modes: In IR spectrum of thiourea ligands, the characteristic bands of the $v(C=S)$ and $v(C-N)$ is expected in the frequency regions; $700-600 \mathrm{~cm}^{-1}$ and at about $1500 \mathrm{~cm}^{-1}$, respectively. As shown in Table-5, a low frequency shift in the $v(C=S)$ bands and a high frequency shift in the $v(\mathrm{C}-\mathrm{N})$ bands are predicted for the complexes compared to free ligands. These spectral shifts are due to the $\mathrm{S} \rightarrow \mathrm{Zn}^{2+}$ coordination where the increase of the interaction between $\mathrm{Zn}^{2+}$ and S-atom.

Frontier molecular orbitals: The frontier molecular orbitals (FMO) can offer a reasonable qualitative prediction of 
TABLE-6

CALCULATED FRONTIER MOLECULAR ORBITALS ENERGIES (eV) FOR THE STUDIED COMPOUNDS

\begin{tabular}{ccccccc}
\hline Compound & $\mathrm{E}_{\text {HOMO }}$ & $\mathrm{E}_{\mathrm{LUMO}}$ & $\Delta \mathrm{E}$ & Compound & $\mathrm{E}_{\mathrm{HOMO}}$ & \multicolumn{1}{c}{$\mathrm{E}_{\mathrm{LUMO}}$} \\
\hline TU & -5.9174 & -0.6599 & 5.2576 & $\mathbf{1}$ & -6.7455 & -0.9701 \\
MTU & -5.7264 & -0.5328 & 5.1936 & $\mathbf{2}$ & -6.5438 & -0.7263 \\
DMTU & -5.5830 & -0.5146 & 5.0684 & $\mathbf{3}$ & -6.3030 & -0.6822 \\
TMTU & -5.4859 & -0.5850 & 4.9008 & $\mathbf{4}$ & -6.4521 & -0.6193 \\
DAT & -5.6121 & -0.4792 & 5.1329 & $\mathbf{5}$ & -1.0868 & 5.1866 \\
\hline TU: Thiourea, MTU: N-methylthiourea, DMTU: N,N'-dimethylthiourea, DAT: diazinane-2-thione, TMTU: tetramethylthiourea
\end{tabular}

the excitation properties and the ability of electron transport ${ }^{15,16}$. The energies of the HOMO and LUMO orbital of studied thiourea ligands; $\mathrm{L}$ and their $\left[\mathrm{ZnL}_{2} \mathrm{Cl}_{2}\right]$ complexes were investigated using DFT/B3LYP method and the results are given in Table- 6 . The results of the FMO energy analysis showed that the energy difference between the HOMO and LUMO decreased due to the presence of alkyl substituent at the $\mathrm{N}$-atom of the studied ligands. In case of the $\left[\mathrm{ZnL}_{2} \mathrm{Cl}_{2}\right]$ complex, the coordination of the $\mathrm{Zn}^{2+}$-ion with the thiourea ligands through the $\mathrm{S}$-atom increases the energy of the HOMO more than the LUMO so, the transition energies are increased and blue shift is predicted.

Non-linear optical properties (NLO): The NLO properties have an important role in communication technology and optical memory devices ${ }^{17}$. The NLO properties are related to the energy gap $(\Delta \mathrm{E})$ between HOMO and LUMO. The smaller $\Delta \mathrm{E}$ value, the more shift of the absorption band towards the visible region ${ }^{18,19}$ and the higher NLO properties. It is found that, the presence of alkyl substituents at the $\mathrm{N}$-sites of thiourea molecule decrease the value of $\Delta \mathrm{E}$ so; increase the NLO properties. These results show that the $\mathrm{N}$-alkyl thiourea ligands are better NLO material than thiourea. In contrast, the calculations predicted larger energy gaps $(\Delta \mathrm{E})$ and so higher excitation energies in case of the $\left[\mathrm{ZnL}_{2} \mathrm{Cl}_{2}\right]$ complexes compared to the free ligands. As a result, the NLO properties are predicted to decrease for the former compared to the latter.

\section{Conclusion}

The molecular geometries and vibrational spectra of five thiourea ligands (L) and their $\left[\mathrm{ZnL}_{2} \mathrm{Cl}_{2}\right]$ complexes are calculated using B3LYP method. There $\mathrm{C}-\mathrm{N}$ bonds are shortened and the $\mathrm{C}-\mathrm{S}$ bonds are elongated due to the coordination of the $\mathrm{Zn}^{2+}$ to the thiourea ligands through the $\mathrm{S}$-atom. As a result a blue shift in the $v(\mathrm{C}-\mathrm{N})$ modes and red shift in the $v(\mathrm{C}-\mathrm{S})$ stretches. The degree of infrared spectral shifts is inversely proportional to the $\mathrm{Zn}-\mathrm{S}$ distances. Careful analysis of the $\mathrm{NH}$ stretching modes predicted red shift for the $\mathrm{v}(\mathrm{N}-\mathrm{H})$ involved in the intramolecular $\mathrm{N}-\mathrm{H}---\mathrm{Cl}$ interactions while the stretching frequencies of the other $\mathrm{v}(\mathrm{N}-\mathrm{H})$ modes undergo blue shift. Molecular electrostatic potential study showed that the zinc ion as electrophile tends to attack on the S-atom of thiourea ligands rather than the $\mathrm{N}$-sites. The atom polar tensor charge analyses confirmed the high polarity of the $\mathrm{C}-\mathrm{N}$ and $\mathrm{C}-\mathrm{S}$ bonds.

\section{REFERENCES}

1. W. Zhou, L. Zhu, Y. Zhang, Z. Yu, L. Lu and X. Yang, Vib. Spect., 36, 73 (2004).

2. M.J. Moloto, M.A. Malik, P.O 'Brien, M. Motevalli and G.A. Kolawole, Polyhedron, 22, 595 (2003).

3. M.R. Malik, V. Vasylyeva, K. Merz, N. Metzler-Nolte, M. Saleem, S. Ali, A.A. Isab, K.S. Munawar and S. Ahmad, Inorg. Chim. Acta, 376, 207 (2011).

4. Y. Omote, R. Kobayashi, C. Kashima and N. Sugiyama, Bull. Chem. Soc. Jpn., 44, 3463 (1971).

5. B.S. Garg and L. Kapur, Inorg. Chim. Acta, 170, 177 (1990).

6. G.M.S. El-Bahy, B.A. El-Sayed and A.A. Shabana, Vib. Spect., 31, 101 (2003).

7. M.J. Frisch, G.W. Trucks, H.B. Schlegel, G.E. Scuseria, M.A. Robb, J.R. Cheeseman, J.A. Montgomery Jr., T. Vreven, K.N. Kudin, J.C. Burant, J.M. Millam, S.S. Iyengar, J. Tomasi, V. Barone, B. Mennucci, M. Cossi, G. Scalmani, N. Rega, G.A. Petersson, H. Nakatsuji, M. Hada, M. Ehara, K. Toyota, R. Fukuda, J. Hasegawa, M. Ishida, T. Nakajima, Y. Honda, O. Kitao, H. Nakai, M. Klene, X. Li, J.E. Knox, H.P. Hratchian, J.B. Cross, V. Bakken, C. Adamo, J. Jaramillo, R. Gomperts, R.E. Stratmann, O. Yazyev, A.J.Austin, R. Cammi, C. Pomelli, J.W. Ochterski, P.Y. Ayala, K. Morokuma, G.A. Voth, P. Salvador, J.J. Dannenberg, V.G. Zakrzewski, S. Dapprich, A.D. Daniels, M.C. Strain, O. Farkas, D.K. Malick, A.D. Rabuck, K. Raghavachari, J.B. Foresman, J.V. Ortiz, Q. Cui, A.G. Baboul, S. Clifford, J. Cioslowski, B.B. Stefanov, G. Liu, A. Liashenko, P. Piskorz, I. Komaromi, R.L. Martin, D.J. Fox, T. Keith, M.A. Al-Laham, C.Y. Peng, A. Nanayakkara, M. Challacombe, P.M.W. Gill, B. Johnson, W. Chen, M.W. Wong, C. Gonzalez and J. A. Pople, Gaussian-03, Revision C.01, Gaussian, Inc., Wallingford, CT (2004).

8. http://www.ccdc.cam.ac.uk/data_request/cif.

9. A.D. Burrows, R.W. Harrington and M.F. Mahon, Acta Crystallogr., 60E, m1317 (2004).

10. R. Dennington II, T. Keith and J. Millam, Gauss View, Version 4.1, Semichem Inc., Shawnee Mission, KS (2007).

11. Y. Mido, H. Okada, N. Fujita, I. Kitagawa, T. Kitahata, M. Hashimoto, H. Yoshida and H. Matsuura, J. Mol. Struct., 415, 215 (1997).

12. M.P. Andersson and P. Uvdal, J. Phys. Chem., 109, 2937 (2005).

13. A. Destexhe, J. Smets, L. Adamowicz and G. Maes, J. Phys. Chem., 98, 1506 (1994).

14. Y. Dimitrova and L.I. Daskalova, Spectrochim. Acta A, 71, 1720 (2009).

15. M. Belletete, J.F. Morin, M. Leclerc and G. Durocher, J. Phys. Chem. A, 109, 6953 (2005).

16. D. Zhenming, S. Heping, L. Yufang, L. Diansheng and L. Bo, Spectrochim. Acta A, 78, 1143 (2011).

17. D. Sajan, H. Joe, V.S. Jayakumar and J. Zaleski, J. Mol. Struct., 785, 43 (2006).

18. K.S.Thanthiriwatte and K.M. Nalin de Silva, J. Mol. Struct. THEOCHEM, 617, 169 (2002).

19. R.G. Pearson, Proc. Natl. Acad. Sci. USA, 83, 8440 (1986). 